\title{
Introduction to the Special Section on Practice Contexts: A Glimpse into the Nether World of Public Mental Health Services for Children and Families
}

\author{
Kimberly Hoagwood · David J. Kolko
}

Published online: 30 December 2008

(C) Springer Science+Business Media, LLC 2008

If scientific trends about strengthening knowledge on installation of evidence-based practices are to ever gain a foothold, then a necessary complement - if not precursorto these studies will be knowledge about the practice contexts that surround new services. It is difficult and perhaps foolhardy to try to improve what you do not understand. Implementation of effective services in the absence of knowledge about the contexts of their delivery is likely to be impractical, inefficient, and costly.

The three papers in this issue are firmly ensconced in what is fondly called "real world." Each comes at the challenge of evidence-based installation in a different way. The first paper by Kolko et al. describes a national survey of four hundred therapists participating in an EBP training on Trauma-focused CBT for children and adolescents. The second paper also by Kolko et al. describes findings from interviews conducted with a sample of 89 child welfare administrators across the country about agency and system issues that impede or facilitate delivery of mental health services. The third paper by Herschell et al. describes different methods for improving knowledge about and skills for delivering a specific evidencebased practice-parent-child interaction therapy-among community based mental health therapists. All three of these papers describe from different vantage points-i.e., therapists, administrative managers, and program evaluators-core

\section{K. Hoagwood ( $\square)$}

Division of Mental Health Policy \& Services Research,

Columbia University, New York, NY, USA

e-mail: hoagwood@childpsych.columbia.edu

\section{J. Kolko}

Department of Psychiatry, Psychology \& Pediatrics, Special

Services Unit Western Psychiatric Institute and Clinic,

University of Pittsburgh School of Medicine, Pittsburgh,

PA, USA elements of real world practice that are likely to impact uptake and delivery of evidence-based practices. The elements that are described include provider attitudes, beliefs, and expectations as well as agency structures, financing methods, linkages and supervisory practices. Each of these elements, if not acknowledged and understood, can pose enormous obstacles to the introduction of new practices.

There are several reasons why a glimpse into the nether world of service practices is needed. First, the databases that are available to describe the public mental health system for children and families are severely limited in their scope, availability and content about both services and about the workforce that delivers these services. Basic descriptive data about agency or program operations, staffing patterns, supervisory practices, and electronic technologies for tracking service visits, much less the content of services, are simply not available to either the public or to researchers. Consequently, program implementers or services researchers wanting to embed new practices in routine care settings are unable to anticipate the many challenges ahead because the context of delivery has not been elucidated, operationalized, or deconstructed. If a more thorough understanding about real world practices existed, then factors that mediate or moderate implementation could be identified and potentially manipulated. In the absence of such knowledge, implementation studies are often launched in a vacuum.

Second, these papers set the stage for an important next generation of studies that can take advantage of the robust basic science on behavior change and the emerging cognitive neurosciences to apply innovative approaches to change the practices of providers, organizations and potentially even communities. For example, drawing on theory of reasoned action (Fishbein 1980) theory of planned behavior (Ajzen 1991), and more recently the unified theory of behavior change (Jaccard et al. 2002), new 
studies are applying specific change strategies to improve employment skills training programs in psychiatric rehabilitation (Casper 2007); family support programs for empowering parents (Olin et al. under review); healthcare professionals' behavior (Eccles et al. 2005), and guideline implementation (Davies et al. 2003). These change strategies, when applied to community practice that is enriched by knowledge about provider and agency characteristics, may enable better matching of treatment and service innovation to the needs and repertoires of the community practitioner, and more efficiency in delivery of services.

The possibilities for effecting fundamental changes in the public mental health system will depend in part on innovations that can bust free from the mundane models that characterize much of current workforce training. Unfortunately, this includes many current approaches to EBP training. Innovations will need to draw upon deeper and more complex understandings from both the neurosciences and the basic behavioral sciences to create not simply new therapies or training programs but learning organizations that are characterized by inquisitiveness, curiosity, and continual intellectual openness. Models and ideas that can be distilled from these more basic sciences, if applied to real world organizational change, offer considerable promise for such a breakthrough. The papers in this special section lift the corner of the tent to reveal new possibilities.

\section{References}

Ajzen, I. (1991). The theory of planned behavior. Organizational Behavior and Human Decision Processes, 50, 179-211.

Casper, E. S. (2007). The theory of planned behavior applied to continuing education for mental health professionals. Psychiatric Services, 58, 1324-1329.

Davies, P., Walker, A., \& Grimshaw, J. (2003). Theories of behavior change in studies of guideline implementation. Proceedings of British Psychological Society, 11, 120.

Eccles, M., Grimshaw, J., Walker, A., Johnston, M., \& Pitts, N. J. (2005). Changing the behavior of healthcare professionals: The use of theory in promoting the uptake of research findings. Journal of Clinical Epidemiology, 58(2005), 107-112.

Fishbein, M. (1980). A theory of reasoned action: Some applications and implications. In H. Howe \& M. Page (Eds.), Nebraska Symposium on Motivation, 1979 (pp. 65116). Lincoln: University of Nebraska Press.

Jaccard, J., Dodge, T., \& Dittus, P. (2002). Parent-adolescent communication about sex and birth control: A conceptual framework. New Directions for Child \& Adolescent Development, 97, 941. 